\title{
Citronellol Induces Necroptosis of Human Lung Cancer Cells via TNF- $\alpha$ Pathway and Reactive Oxygen Species Accumulation
}

\author{
WAN-NIEN YU ${ }^{1}$, YING-JU LAI ${ }^{2,3}$, JUI-WEN MA ${ }^{4}$, CHI-TANG HO ${ }^{5}$, SHAN-WEI HUNG ${ }^{4}$, \\ YU-HSIN CHEN ${ }^{6}$, CHIUNG-TONG CHEN $^{2,3,7}$, JUNG-YIE KAO ${ }^{4}$ and TZONG-DER WAY WH $^{4,7,8}$
}

${ }^{1}$ Department of Otolaryngology, Head and Neck Surgery, Changhwa Christian Hospital, Changhwa, Taiwan, R.O.C.;

${ }^{2}$ Institute of Bioinformatics and Structural Biology, National Tsing Hua University, Hsinchu, Taiwan, R.O.C.;

${ }^{3}$ Institute of Biotechnology and Pharmaceutical Research, National Health Research Institutes, Miaoli, Taiwan, R.O.C.;

${ }^{4}$ Institute of Biochemistry, College of Life Science, National Chung Hsing University, Taichung, Taiwan, R.O.C.;

${ }^{5}$ Department of Food Science, Rutgers University, New Brunswick, NJ, U.S.A.;

${ }^{6}$ Taichung District Agricultural Research and Extension Station, Council of Agriculture, Taichung, Taiwan, R.O.C.;

${ }^{7}$ Department of Biological Science and Technology, College of Biopharmaceutical and

Food Sciences, China Medical University, Taichung, Taiwan, R.O.C.;

${ }^{8}$ Department of Health and Nutrition Biotechnology, College of Health Science, Asia University, Taichung, Taiwan, R.O.C.

\begin{abstract}
Background/Aim: Our current study aimed to determine the molecular mechanisms of citronellol-induced cell death and ROS accumulation in non-small cell lung cancer (NCI-H1299 cells) and also compare the anticancer effects of citronellol and EOPC. Materials and Methods: ROS measurement and western blotting were performed to detect whether citronellol can induce necroptosis in vitro. Besides, we performed an in vivo analysis of tumourigenesis inhibition by citronellol treatment in $B A L B / c(n u / n u)$ nude mice. Results: Necroptosis occured by up-regulating TNF- $\alpha$, RIPI/RIP3 activities, and down-regulating caspase-3/caspase-8 activities after citronellol treatment in NCI-H1299 cells. Citronellol also resulted in a biphasic increase in ROS production at $1 \mathrm{~h}$ and
\end{abstract}

This article is freely accessible online.

Supplementary material: The supplementary data of the manuscript are freely available at: https://drive.google.com/file/d/1KgSozm Rss2kJbmuiGN31pdtxjRgh1sST/view?usp=sharing

Correspondence to: Tzong-Der Way, Ph.D., Department of Biological Science and Technology, College of Life Sciences, China Medical University, No.91, Hsueh-Shih Road, Taichung, 404, Taiwan, R.O.C. Tel: +886 422053366 ext: 2509, Fax: +886 422031075, e-mail: tdway@mail.cmu.edu.tw; Jung-Yie Kao, Ph.D., Institute of Biochemistry, College of Life Science, National Chung Hsing University, Taichung, No.250, Kuo Kuang Rd., Taichung 402, Taiwan, R.O.C. Tel: +886 422840468 ext.: 222, Fax: +886 422853487, e-mail: biosjky@gmail.com

Key Words: Citronellol, essential oil of Pelargonium capitatum (EOPC), necroptosis, non-small-cell lung cancer (NSCLC), reactive oxygen species (ROS). at 12 h in NCI-H1299 cells. Xenograft model experiments showed that citronellol could effectively inhibit subcutaneous tumours produced 4 weeks after intraperitoneal injection of NCI-H1299 in BALB/c nude mice. Conclusion: Citronellol induced necroptosis of NCI-H1299 cells via TNF- $\alpha$ pathway and ROS accumulation.

Lung cancer is one of the most common cancers in the world. More than 2.0 million new cases are diagnosed each year. The World Health Organization (WHO) divides lung cancer into non-small-cell lung carcinoma (NSCLC) and small-cell lung carcinoma (SCLC). NSCLC accounts for 80$85 \%$ of all lung cancer cases, is characterized by high recurrence rate and drug resistance, and its 5-year survival rate is about $15-20 \%(1-4)$. This underlines the need to develop effective drugs for treatment and overcome the clinical challenges involved in NSCLC (5).

Necrosis is an acute form of cell death triggered by unexpected injuries $(6,7)$, which destroy cell structure. When apoptosis fails to occur, cells die by necrosis (8). Necrosis is divided into non-programmed necrosis (or simply necrosis) and programmed necrosis (or necroptosis), depending on whether it is initiated by the activation of a specific receptor or sensor on the cell surface or inside the cell to induce a multi-step signal transduction, as well as a variety of molecular biological reactions (9). Several receptor-mediated signal transduction pathways are involved in necroptosis. For example, binding of tumor necrosis factor- $\alpha$ (TNF- $\alpha)$ to TNFR induces programmed cell death pathway. TNFR-associated death domain (TRADD) is associated with the receptor-interacting protein kinase 1 (RIP1), cellular apoptosis inhibitor 1/2 (cIAP1/2) and TNFR- 


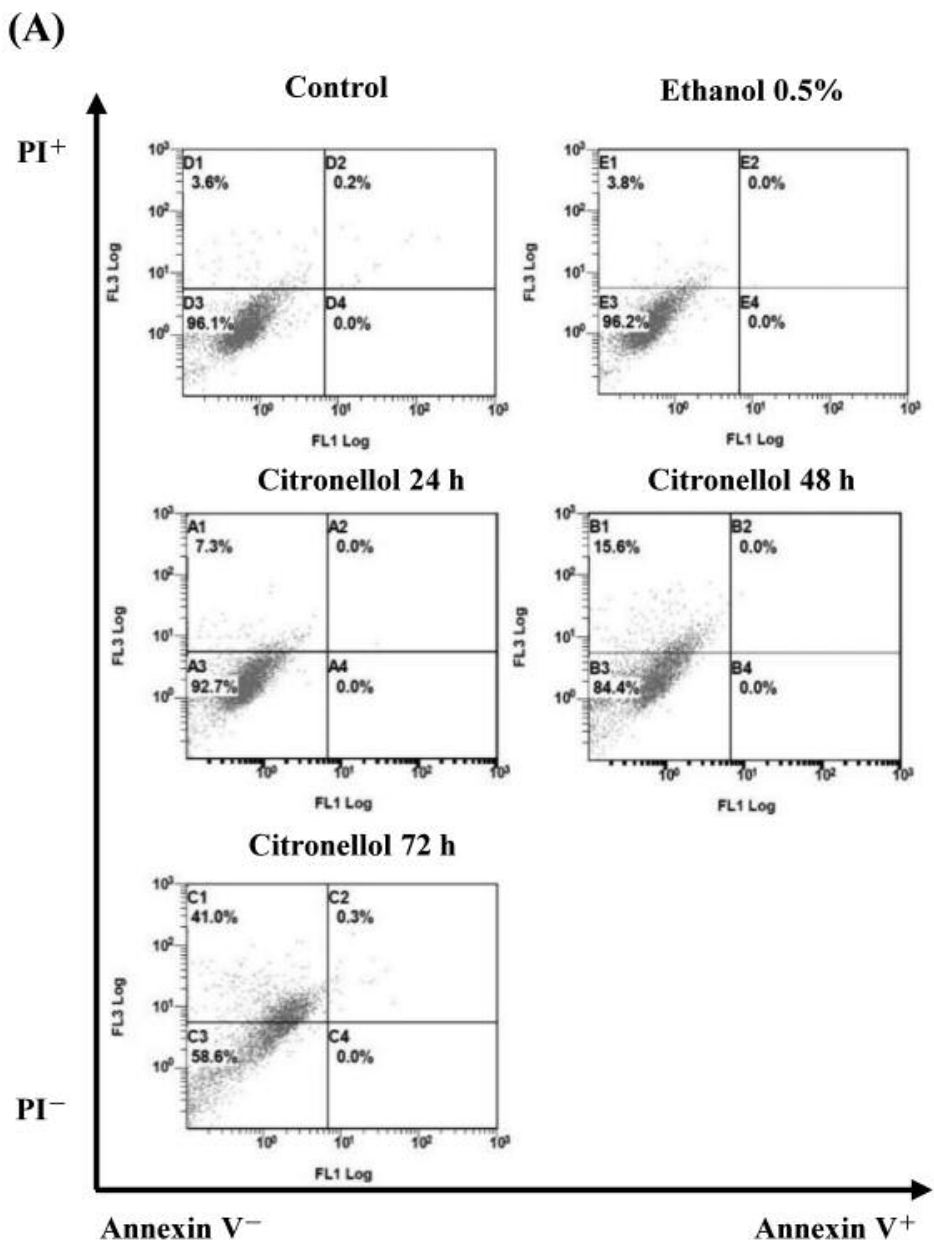

Figure 1. Continued

associated factor $2 / 5$ (TRAF2/5), forming the RIPK1dependent complex I. Subsequently, RIP1 is deubiquitylated by ubiquitin carboxyl-terminal hydrolase (CYLD) and then combine with multiple RIP3, Fas-Associated protein with Death Domain (FADD), TRADD and caspase 8 to form Complex IIb, also known as Necrosome $(10,11)$. In the case where caspase 8 is inhibited, RIP1 will be autophosphorylated at position Ser161, and RIP3 will also phosphorylate RIP1 directly or indirectly, leading Complex IIb to enter the Necroptosis program. The RIP3/ mixed lineage kinase domain-like (MLKL) regulatory mechanism is upregulated, allowing multiple phosphorylated MLKL molecules to form a complex that induces cell necroptosis (12-14). Later, energy depletion, oxidative stress due to reactive oxygen species (ROS) accumulation, and lysosomal membrane permeabilization (LMP) occur, ultimately leading to cell death. Another marker of apoptosis is the proteolytic cleavage of poly (ADP-ribose) polymerase (PARP), a nuclear enzyme involved in DNA repair, DNA stability, and transcriptional regulation. PARP is proteolytically inactivated during apoptosis (15-17), but is activated during necroptosis because of inhibition of caspase 8 (18-20). Activated complexes I, II can increase calcium and calpain, respectively, leading to lipid peroxidation and activation of cathepsin $\mathrm{B} / \mathrm{D}$ which is released into the cytoplasm to induce necroptosis (21).

In preliminary experiments (see Supplementary material), essential oil of Pelargonium capitatum (EOPC) was found to induce necrosis in NSCLC. EOPC is a mixture that is limited in its effectiveness in inducing cancer cell death. Citronellol has been identified by gas chromatography-mass spectrometry (GC-MS) as the most abundant component of EOPC (22). Citronellol is a monoterpene having the molecular formula of $\mathrm{C}_{10} \mathrm{H}_{20} \mathrm{O}$. Some natural essential oils contain either (+)-citronellol or (-)-citronellol, and the corresponding racemic mixture. (+)-Citronellol is mainly found in amyris, citronella, and eucalyptus citriodora oils, while (-)-citronellol is mainly found in rose and 
(B)

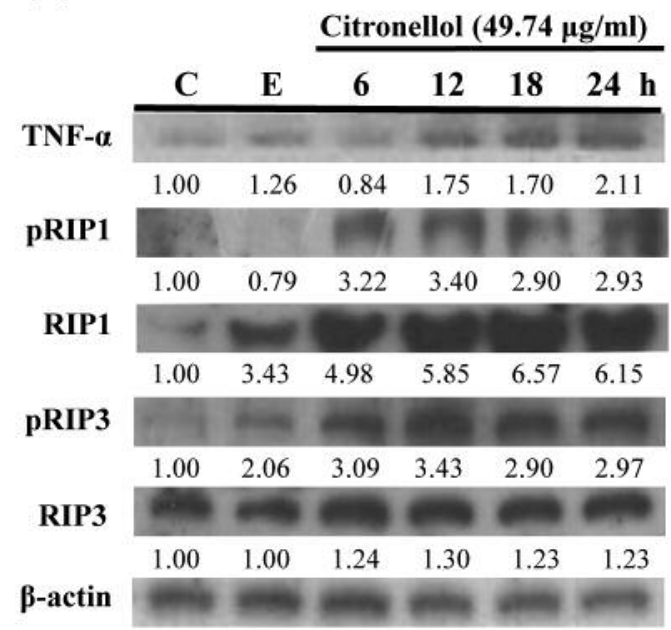

(C)

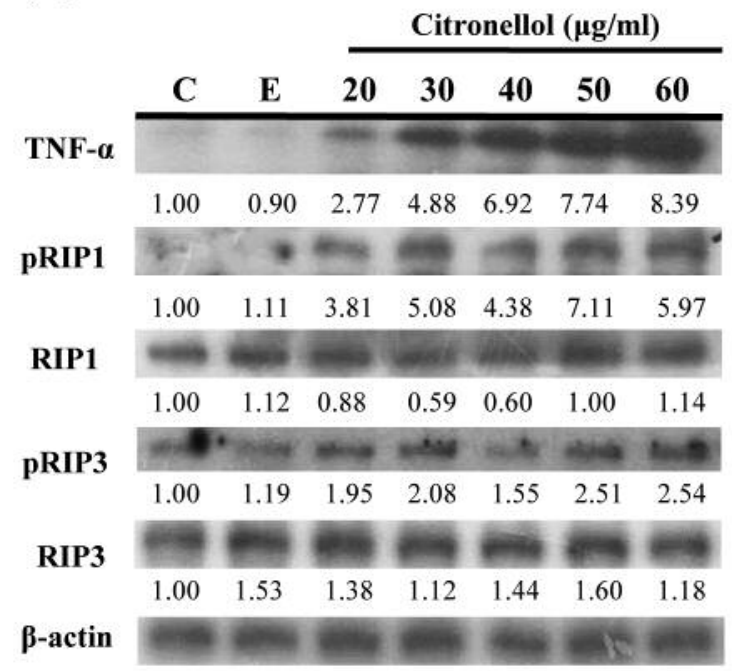

(D)

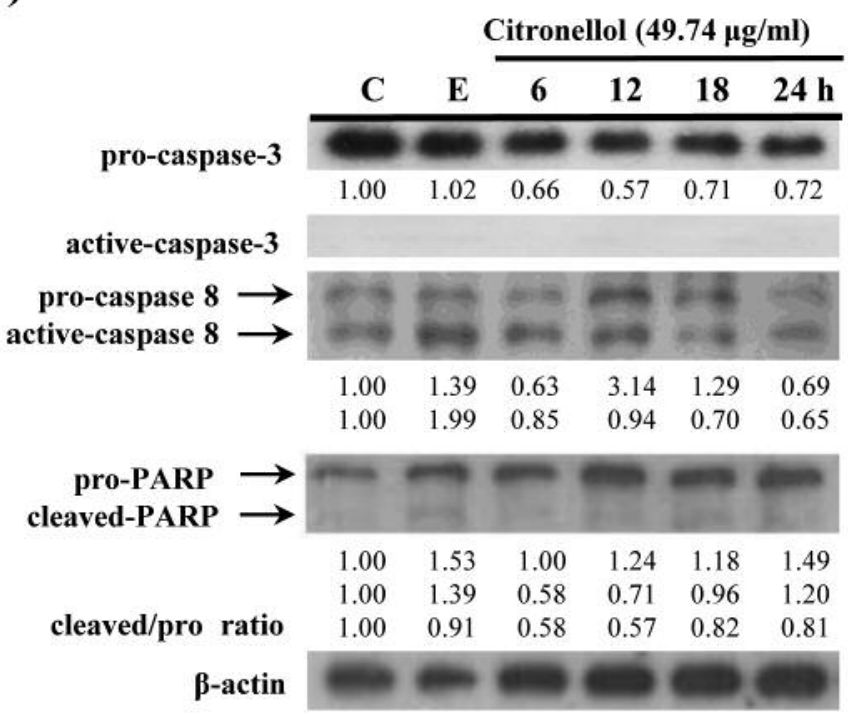

(E)

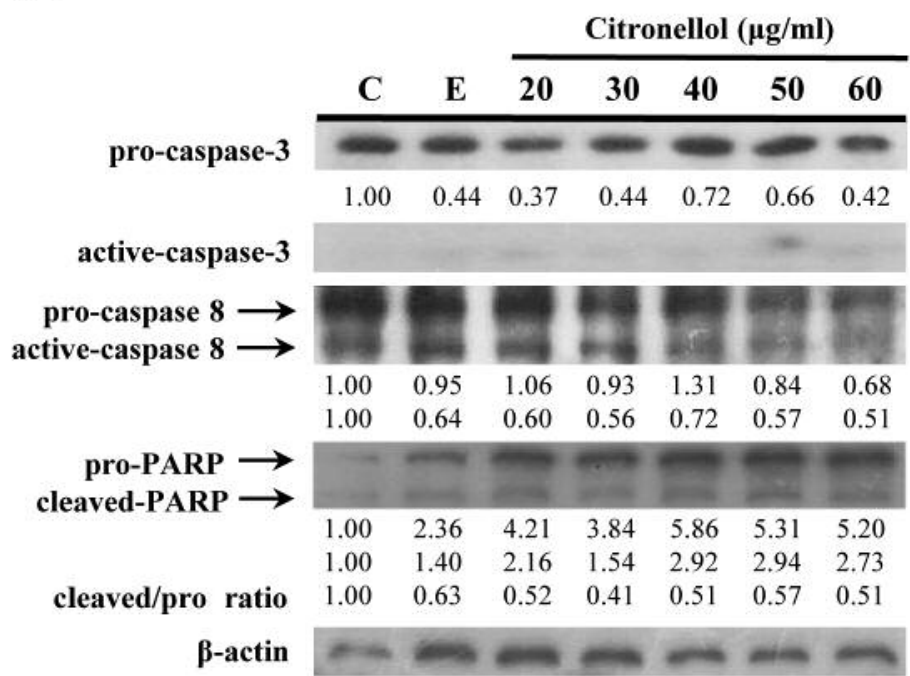

Figure 1. Citronellol induced necroptosis in NCI-H1299 cells. (A) NCI-H1299 cells treated with $49.74 \mu \mathrm{g} / \mathrm{ml}(24 \mathrm{~h}$ IC 50$)$ citronellol for 24,48 and $72 \mathrm{~h}$. Cells were stained with FITC-conjugated Annexin V-PI and measured by flow cytometry. Control: $24 \mathrm{~h}+$ medium: Ethanol $0.5 \%, 24 \mathrm{~h}+$ ethanol $0.5 \%+$ medium. (B) NCI-H1299 cells were treated with $49.74 \mu \mathrm{g} / \mathrm{ml}$ citronellol for $6,12,18$ and 24 h. Cells lysates were immunoblotted with TNF- $\alpha$, phosphoRIP3, phosphoRIP1 antibodies, and $\beta$-actin was used as the loading control. Numbers below represented the relative protein quantitation. C: control, $24 h+$ medium; E: $24 h+$ Ethanol $0.5 \%+$ medium. $(C)$ Western blot data. (D) Western blot data for pro/active caspase3, pro/active caspase 8 and pro/cleaved PARP. (E) Western blot data. Experiments were repeated at least three times.

pelargonium oils (both are colorless liquids with a rose scent). Citronellol inhibits the activities of Staphylococcus aureus and Salmonella typhi $(23,24)$ and also has strong inhibitory effect on Candida albicans (25), which can be used as an antioxidant and anti-inflammatory agent in rodents (26). It has been shown that treatment with citronellol in patients receiving chemotherapy and/or radiotherapy reduces side effects of therapy (such as nausea, dysgeusia, numbness of the extremities, and hearing loss) and lowers the depletion of leukocytes and neutrophils to improve their immune function (27).

The aim of the current study was to determine the molecular mechanisms of citronellol induced cell death and ROS accumulation in non-small cell lung cancer (NSCLC) NCI-H1299 cells, and also to compare the anticancer effects of citronellol and EOPC in NCI-H1299 cells. 


\section{Materials and Methods}

Chemicals. [(S)-( \pm )- $\beta$-Citronellol, CT, 97\% purity], 3-(4, 5dimethylthiazol-2-yl)-2, 5-diphenyl tetrazolium bromide (MTT) and propidium iodide (PI) were purchased from Sigma (St. Louis, MO, USA). EOPC was a kind gift from Dr. Yuhsin Chen (Taichung District Agricultural Research and Extension Station, Council of Agriculture, Taichung, Taiwan). Antibodies against caspase-3 (GTX110543, 1:1000), cathepsin B (GTX63008, 1:1000) and cathepsin D (GTX62063, 1:1,000) were purchased from GeneTex (Beverly, MA, USA). Antibodies against RIP1 (sc-133102, 1:100), RIP3, cyclin E (sc-247, 1:500), caspase-8 and CDK2 (sc-6248, 1:500) were purchased from Santa Cruz Biotechnology (Santa Cruz, CA, USA). Antibodies against phophoRIP1 (Ser166, \#65746, 1:500), PARP (\#9542, 1:1,000) and TNF- $\alpha$ (\#3707, 1:500) were from Cell Signaling Technology (Beverly, MA, USA). Antibody against phophoRIP3 (S227, ab209384, 1:500) was purchased from Abcam. Antibody against $\beta$-actin was purchased from Millipore (Temecula, CA, USA). Horseradish peroxidase (HRP)-conjugated Goat anti-Mouse IgG and Goat anti-Rabbit IgG were obtained from Millipore.

Cell culture. Human NSCLC cell lines A549, NCI-H23, NCIH1299, Triple Negative Breast Cancer (TNBC) cell line BT-20, human prostate cancer cell line PC3 and normal breast epithelial cell line MCF-10A were obtained from the American Type Culture Collection (Manassas, VA, USA). A549, NCI-H23 and MCF-10A cells were cultured in DMEM/F12 (Invitrogen, Carlsbad, CA, USA) supplemented with $10 \%$ FBS and $1 \%$ penicillin-streptomycin. BT20, NCI-H1299 and PC3 cells were cultured in RPMI-1640 (Invitrogen) supplemented with 10\% FBS (Invitrogen) and 1\% penicillin-streptomycin and incubated in an incubator containing 5\% $\mathrm{CO}_{2}$ at $37{ }^{\circ} \mathrm{C} .3-(4,5-$ Dimethylthiazol-2-yl)-2,5-diphenyltetrazolium bromide (MTT) assay. MTT assay was employed to evaluate cell viability of citronellol-treated A549, NCI-H23, NCI-H1299, BT-20, PC3 and MCF-10A cells. Cells $\left(5 \times 10^{4}\right.$ per well) were cultured in 24-well plate, after $24 \mathrm{~h}$ of growth, the cells should reach about $95 \%$ confluence as a monolayer. After 24 and $48 \mathrm{~h}$ of treatment with citronellol, $40 \mu \mathrm{l}$ of MTT working solution $(5 \mu \mathrm{g} / \mathrm{ml})$ was added and incubated at $37^{\circ} \mathrm{C}$ for $2 \mathrm{~h}$ until purple crystals appeared. The medium was carefully removed, DMSO $(200 \mu \mathrm{l} /$ well $)$ was added, and after the crystals were completely dissolved, each $100 \mu \mathrm{l}$ was placed in a 96-well plate. The optical density was measured using an ELISA reader at $570 \mathrm{~nm}$ wavelength.

Annexin V-PI assay. The Annexin V-FITC Apoptosis Kit (BioVision, Milpitas, CA, USA) was used according to the manufacturer's protocol. Briefly, cells were rinsed briefly with PBS and detached with trypsin at room temperature. After centrifugation, cells were resuspended in $500 \mu \mathrm{l} 1 \mathrm{X}$ binding buffer. Then $5 \mu \mathrm{l}$, Annexin VFITC and $5 \mu \mathrm{PI}$ were added and incubated for $5 \mathrm{~min}$ at room temperature in the dark. The cell suspension was analyzed for DNA content by flow cytometry (BD Biosciences, San Jose, CA, USA).

Protein extraction and western blot analysis. Cells $\left(1 \times 10^{6}\right)$ were treated with various agents as indicated in figure legends. Harvested cells were lysed with $400 \mu \mathrm{l}$ of lysis buffer $(50 \mathrm{mmol} / \mathrm{l}$ Tris- $\mathrm{HCl}$, $\mathrm{pH} 8.0,150 \mathrm{mmol} / \mathrm{l} \mathrm{NaCl}, 0.1 \%$ SDS, $1 \%$ Nonidet P-40, $0.5 \%$ sodium deoxycholate, $0.02 \%$ sodium azide, $100 \mu \mathrm{g} / \mathrm{ml}$ phenylmethylsulfonyl fluoride, $1 \mu \mathrm{g} / \mathrm{ml}$ aprotinin). Protein concentration was determined according to the Bradford method
Table I. The IC 50 of citronellol induced toxicity in A549, NCI-H1299, NCI-H23, BT-20, PC3 and MCF-10A cells treated for $24 \mathrm{~h}$ and $48 \mathrm{~h}$.

\begin{tabular}{lcc}
\hline & $24 \mathrm{~h} \mathrm{IC}_{50}(\mu \mathrm{g} / \mathrm{ml})$ & $48 \mathrm{~h} \mathrm{IC}_{50}(\mu \mathrm{g} / \mathrm{ml})$ \\
\hline A549 & 69.10 & 54.02 \\
NCI-H1299 & 49.74 & 40.64 \\
NCI-H23 & 63.53 & 52.51 \\
BT-20 & 61.23 & 45.84 \\
PC3 & 60.83 & 50.10 \\
MCF-10A & - & - \\
\hline
\end{tabular}

(Bio-Rad Laboratories, Hercules, CA, USA). A total of $50 \mu \mathrm{g}$ of protein extract were loaded into sodium dodecyl sulphate polyacrylamide gels, and the separated proteins were transferred to nitrocellulose filters. The blotted membrane was blocked with 5\% skim milk for $1 \mathrm{~h}$ at room temperature and probed with the appropriate primary antibody overnight at $4^{\circ} \mathrm{C}$. Finally, HRPconjugated appropriate secondary antibody was added for $1 \mathrm{~h}$. Signals from the bound antibodies were detected with an ECL chemiluminescence kit (Amersham Biosciences, London, UK).

Reactive oxygen species measurement. Cells at a density of $5 \times 10^{5}$ cells seeded in a $10 \mathrm{~cm}$ dish and incubated for $24 \mathrm{~h}$ were treated with $49.74 \mu \mathrm{g} / \mathrm{ml}$ citronellol for the indicated time. $10 \mu \mathrm{l}$ of $4 \mu \mathrm{M}$ H2DCFDA were added to cells after washing twice with PBS and incubated for $30 \mathrm{~min}$ in a conventional incubator $\left(37^{\circ} \mathrm{C}, 5 \% \mathrm{CO}_{2}\right)$ in the dark. Cells were trypsinized and immediately analyzed for fluorescence intensity of DCF by flow cytometry. ROS accumulation was assessed by multicycle software.

In vivo studies. This project was approved by the Institutional Animals Care and Use Committee of China Medical University, Taiwan. In vivo tumourigenesis inhibition was determined by subcutaneous injection of $2 \times 10^{6} \mathrm{NCI}-\mathrm{H} 1299$ cells in the hind flank of 7-week-old BALB/c (nu/nu) nude mice, according to the Guide for the Care and Use of Laboratory Animals published by the US National Institutes of Health (NIH Publication No. 85-23, revised 1996). Mice were divided into four groups (5 mice per group) after tumour volumes were grown larger than $100 \mathrm{~mm}^{3}$, and treated daily with vehicle alone (10\% ethanol in PBS solution) or various doses of citronellol $(12.5,25$, and $50 \mathrm{mg} / \mathrm{kg}$ ) through intraperitoneal injection, 5 days per week for 4 consecutive weeks. Tumour growth inhibition was determined by measuring tumour size twice a week by a digital caliper. Tumour volume was calculated by (width $\times$ length $\left.{ }^{2}\right) / 2$.

Statistical analysis. S.D. was calculated from three independent experiments. $p$-Values were analyzed by Student's $t$-test to compare the continuous variables between two groups, with a two-tailed method $(* p<0.05 ; * * p<0.01 ; * * * p<0.001)$.

\section{Results}

Cytotoxicity of citronellol for NSLCL, breast cancer, prostate cancer and normal breast cells. The anti-tumour activity of citronellol was evaluated against NSCLC cells A549, NCIH23, NCI-H1299, BT-20, PC3 and MCF-10A. Cells were 
(A)

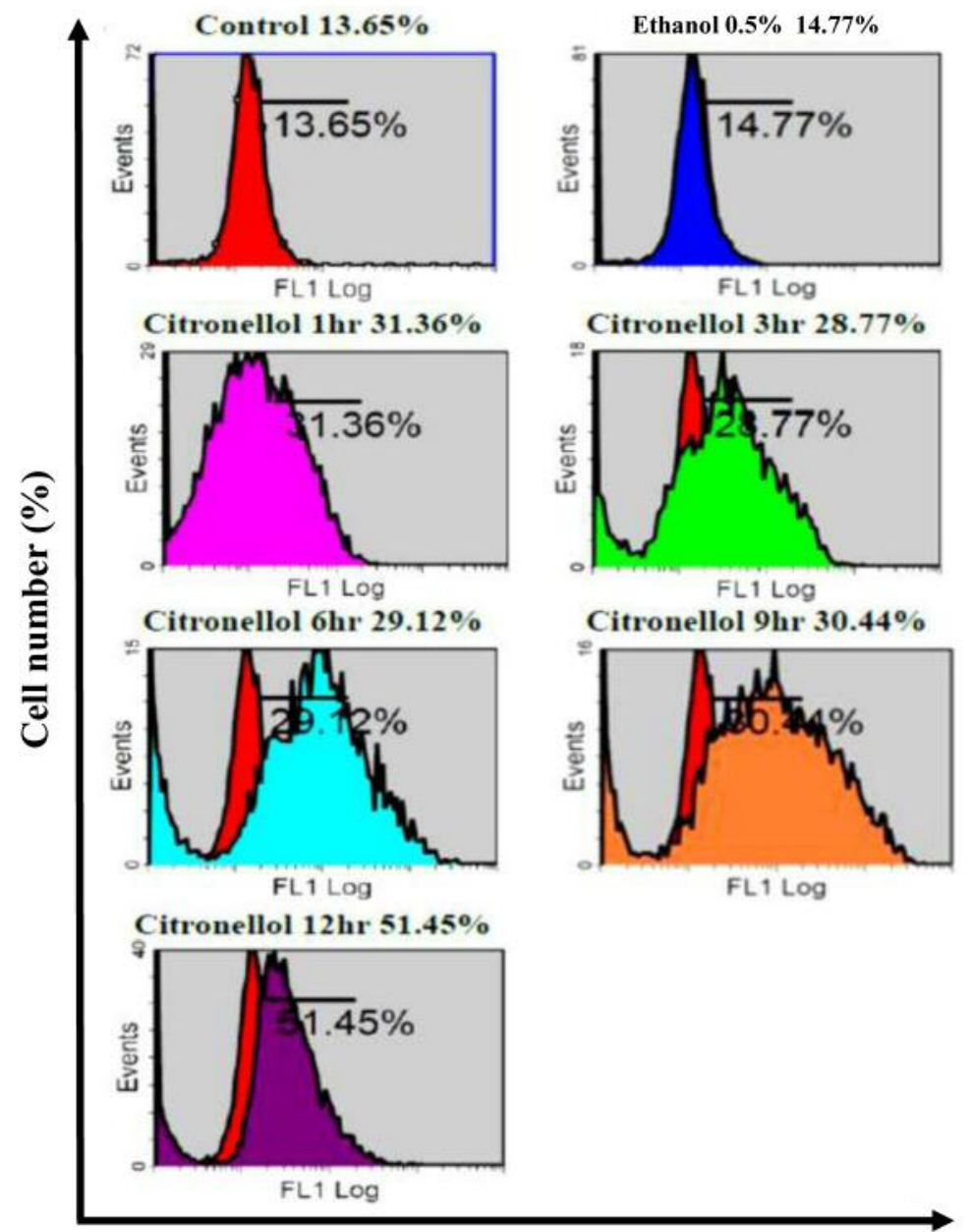

(B)

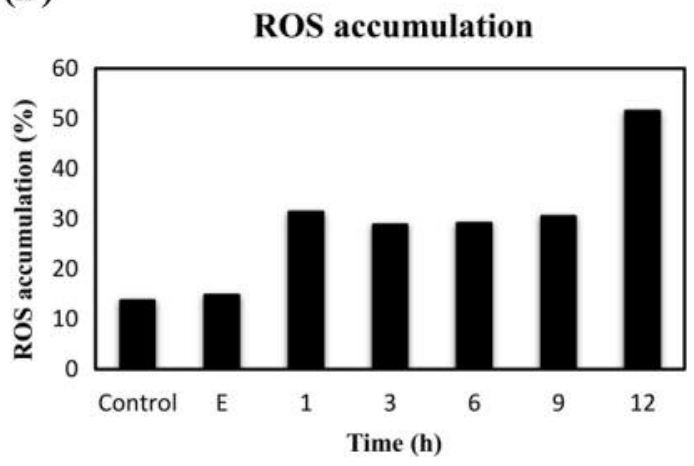

(C)

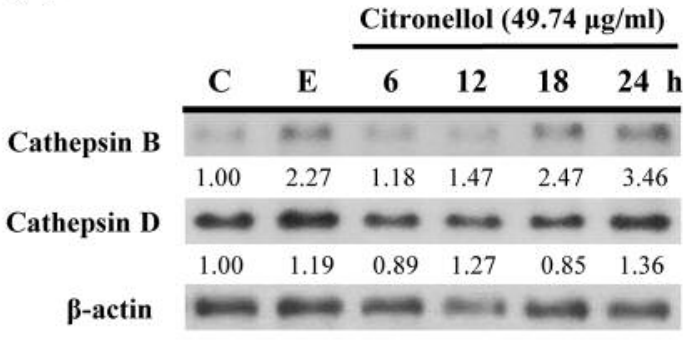

Fluorescence intensity

Figure 2. Citronellol induced ROS accumulation in NCI-H1299 cells. (A) NCI-H1299 treated with $49.74 \mu \mathrm{g} / \mathrm{ml}$ citronellol for 1, 3, 6, 9 and $12 \mathrm{~h}$. Cells were stained with H2DCF-DA and fluorescence intensity of DCF was detected by flow cytometry. Control: $24 \mathrm{~h}+$ medium, Ethanol $0.5 \%$ : $24 \mathrm{~h}+$ Ethanol $0.5 \%+$ medium. (B) ROS accumulation was quantified by Multicycle software; X-axis represents the time to treat citronellol and $Y$-axis represents the fluorescence intensity of DCF (proportional to ROS accumulation). (C) NCI-H1299 cells were treated with $49.74 \mu \mathrm{g} / \mathrm{ml}$ citronellol for 6, 12, 18 and $24 \mathrm{~h}$, followed by western blot analysis for cathepsin B and D expression. $\beta$-actin was used as the loading control and the numbers below represented the relative protein quantitation. Control: $24 h+$ medium, E: $24 h+$ Ethanol $0.5 \%+$ medium. The experiments were repeated at least three times.

treated with different concentrations of citronellol for 24 and $48 \mathrm{~h}$ and cell viability was assessed by the MTT assay. The results showed that citronellol had toxic effect on all five cancer cell lines, but had no effect on normal cells (MCF-10A) (Suppl. Figure 1C, D). Table I illustrates the $\mathrm{IC}_{50}$ of citronellol in different cancer cell lines. Citronellol had the best inhibitory effect on non-small-cell lung cancer NCI-H1299 cells, therefore, NCI-H1299 cells were used in subsequent studies.

Effect of citronellol on the cell cycle of NCI-H1299. Propidium iodide (PI) staining was employed to analyze the NCI-H1299 cell cycle. Citronellol treatment resulted in retention of cells in the G1 phase of the cell cycle, and in a decrease in the number of cells in the S-phase (Suppl. Figure 2C, D). Expression of cyclin $\mathrm{E}$, cyclin D and CDK2 $(28,29)$ which are involved in the transition from $G_{1}$ to $S$ was examined using western blotting. Citronellol treatment resulted in statistically significant time-dependent reduction in the levels of cyclin E, cyclin D and CDK2 (Suppl. Figure 3B).

Citronellol induced necroptosis in NCI-H1299 cells. To further clarify the mechanism citronellol-induced NCI- 
(A)

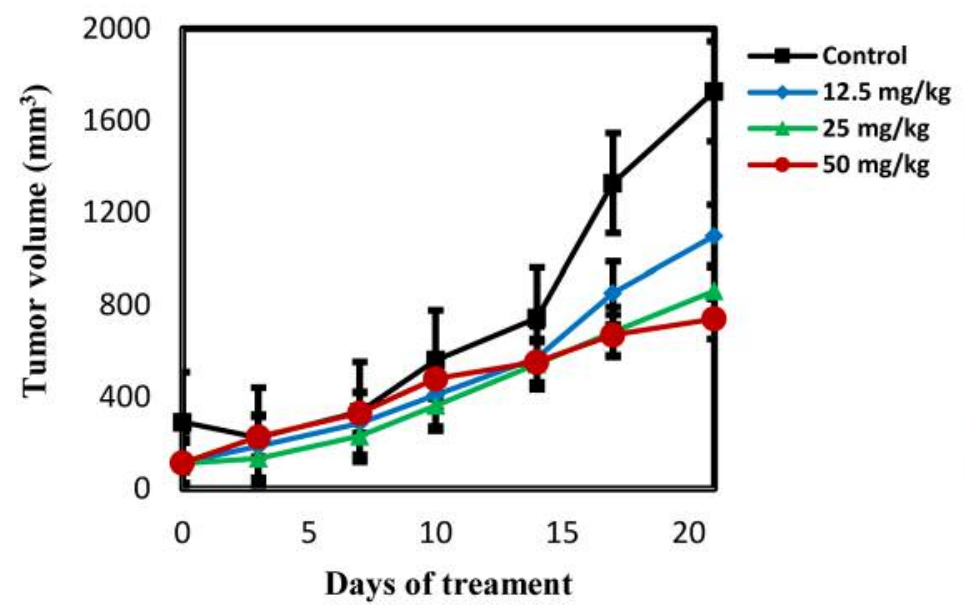

(B)

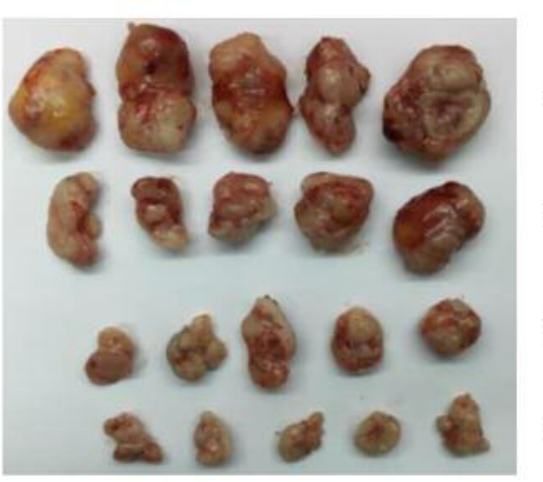

\section{Control}

$12.5 \mathrm{mg} / \mathrm{kg}$

$25 \mathrm{mg} / \mathrm{kg}$

$50 \mathrm{mg} / \mathrm{kg}$

Figure 3. Effects of citronellol on tumour growth. NCI-H1299 cells were used to establish xenografts in male BALB/c nude mice. Animals (5 mice/group) were administered vehicle, citronellol $(12.5,25$ and $50 \mathrm{mg} / \mathrm{kg}$ ) by intraperitoneal injection 5 days per week for 4 consecutive weeks. (A) Tumour size was monitored through serial caliper measurements twice a week. Each point represents mean tumour size \pm SE. (B) Representative tumours in each group were demonstrated.

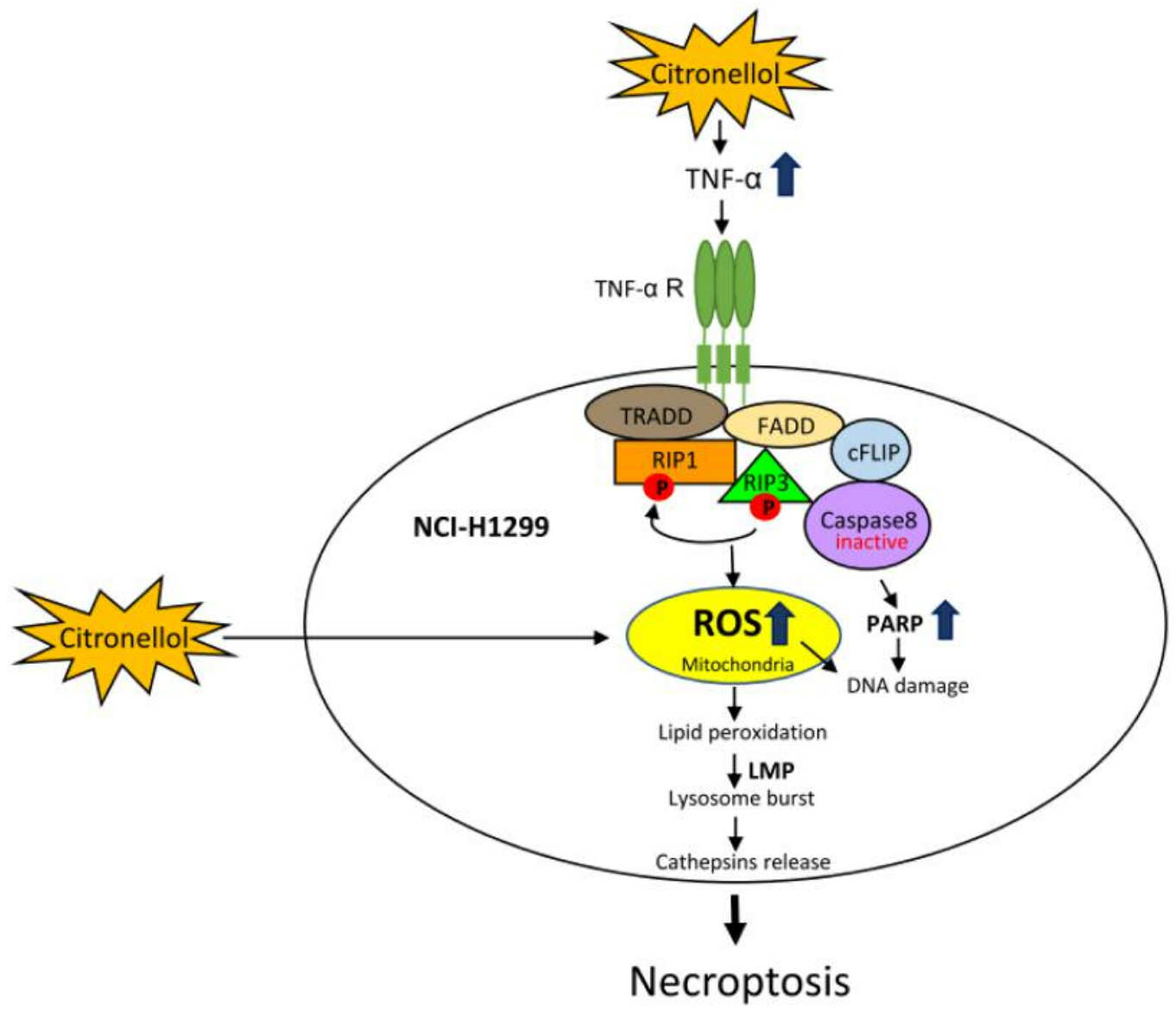

Figure 4. Summary of citronellol-induced necroptosis and ROS accumulation in human lung cancer NCI-H1299 cells. 
H1299 cell death, Annexin V-PI double staining was used. The results indicated that citronellol induced NCI-H1299 cell death by cell necrosis (Figure 1A). To elucidate citronellolinduced cell death signaling pathway, HCI-H1299 cells were treated for $6,12,18$, and $24 \mathrm{~h}$ with citronellol and the expression of TNF- $\alpha$, phosphorylated RIP1 (Ser166) and phosphorylated RIP3 (Ser227) was examined by western blotting. The results showed that TNF- $\alpha$ expression and RIP1, RIP3 activity increased in a time-depedent manner after treatment of NSCLC cells with $49.74 \mu \mathrm{g} / \mathrm{ml}(24 \mathrm{~h}$, $\mathrm{IC}_{50}$ ) citronellol (Figure 1B). NCI-H1299 cells were also treated with $20-60 \mu \mathrm{g} / \mathrm{ml}$ citronellol for $24 \mathrm{~h}$ to analyse TNF$\alpha$ expression and RIP1, RIP3 activity (Figure 1C). Following treatment with citronellol, TNF- $\alpha$ expression and RIP1 / RIP3 activation were significantly up-regulated in the time and dose-dependent manner. In summary, citronellol induced necroptosis of NCI-H1299 cells by activating downstream RIP1, FADD and RIP3 in the TNF- $\alpha$ pathway, thereby enabling the formation of Complex IIb that induced cell death. Western blot was employed to observe the activation of the DNA repair enzyme PARP, caspase- 3 and caspase- 8 in citronellol-treated NCI-H1299 cells. There were no significant changes in pro-caspase- 3 and pro-caspase- 8 expression, and active-caspase- 3 and active-caspase- 8 expression. In addition, there was no significant increase in cleaved-PARP expression compared to the control group (Figure 1D and E).

Citronellol induced ROS generation in NCI-H1299 cells. Necroptosis is closely related to the production of intracellular ROS. To determine if citronellol can induce ROS production, NCI-H1299 cells were treated with citronellol and then stained with 2,7-dichlorodihydrofluorescein diacetate (H2DCFDA) dye. Flow cytometry was used to estimate the dichlorofluorescein (DCF) fluorescence intensity of the citronelloltreated NCI-H1299, and multicycle software was used to measure the amount of ROS in the cells (Figure 2). Quantification of the DCF staining results (Figure 2B) indicated over-accumulation of ROS following citronellol treatment of NCI-H1299 cells. During necroptosis, cathepsin activity is substantially increased due to rapid ROS accumulation-induced LMP and lysosomal rupture (21). Cathepsins are released into the cytoplasm and degrade the cytoskeletal matrix. NCI-H1299 cells were treated with 49.74 $\mu \mathrm{g} / \mathrm{ml}$ citronellol, harvested at the indicated time points, cathepsin B/D expression was analyzed by western blot. The results showed that cathepsin B expression in the cytoplasm of NCI-H1299 cells increased substantially in a time-depedent manner (Figure 2C).

Anti-tumour activity of citronellol in NSCLC xenografts. To examine whether citronellol suppresses tumourigenesis in vivo, NCI-H1299 cells were subcutaneously implanted into
$\mathrm{BALB} / \mathrm{c}(\mathrm{nu} / \mathrm{nu})$ nude mice. Intraperitonial injection of citronellol induced a dose-dependent inhibition of NCIH1299 tumour volume (Figure 3A and B). There was no significant change in body weight of the mice $(23-25 \mathrm{~kg})$ and no pathologic signs were observed before sacrifice.

\section{Discussion}

In order to assess the functional differences between natural extracts and pure compounds, the effects of EOPC and citronellol on lung cancer cells were compared and the molecular mechanism of citronellol-induced cell death in NCI-H1299 cells was examined. The results of the MTT assay indicated that the toxicity of citronellol to cancer cells was much higher than that of EOPC (Suppl. Figure 1) and both EOPC and citronellol have strong cytotoxic effects in NCI-H1299 cells.

PI staining was used to examine whether EOPC and citronellol affected the cell cycle in NCI-H1299 cells. Both EOPC and citronellol treatment arrested NCI-H1299 cell growth in G1 phase in the time-dependent manner (Figure Suppl. 2). Western blotting of the cell cycle - associated proteins revealed a significant decrease in cyclin $\mathrm{E}$ and cyclin D expression after EOPC or citronellol treatment compared to control group (Suppl. Figure 3). In conclusion, both EOPC and citronellol downregulated the expression of cyclin $\mathrm{E}$ and cyclin $\mathrm{D}$, resulting in the retention of NCIH1299 cells in the G1 phase of the cell cycle.

To further elucidate the pathway by which EOPC or citronellol induced NCI-H1299 cell death, AnnexinV-PI double staining was used. Both, EOPC and cirtonellol induced NCI-H1299 cell death by cell necrosis, but citronellol was more efficient than EOPC (Figure 1A, Suppl. Figure 4A). Increased expression of TNF- $\alpha$ and activation of RIP1/RIP3 without a significant increase in caspase- 3 activity indicated citronellol induced necroptosis of NCI-H1299 cells.

During apoptosis, caspase-3 is activated and reduces cellular energy loss by rapidly cleaving PARP and neutralizing its ability to deplete ATP for DNA repair. However, when necroptosis-induced ROS accumulation leads to DNA damage, PARP synthesis continues and over-activation further leads to repetitive DNA damage and subsequent depletion of ATP and NAD (30). Pro-caspase-3 exhibited no significant changes in EOPC or citronellol-treated NCI-H1299 cells, while expression of active-caspase- 3 was negligible. Furthermore, pro-PARP expression was markedly increased in a dose and time-dependent manner, without an increase in cleaved-PARP, indicating over-activation of PARP in citronellol-treated NCIH1299 cells. By contrast, no significant PARP activation was observed in EOPC-treated NCI-H1299 cells (Figure 1D, E and Suppl. Figure 4B, C). These data suggested that only citronellol activated RIP1, FADD, and RIP3 which are downstream of the TNF- $\alpha$ pathway, allowing them to form 
Complex IIb and induce PARP over-activation to trigger necroptosis in NCI-H1299 cells.

Excessive accumulation of ROS during necroptosis lesds to oxidative stress and DNA damage. These free radicals also attack unsaturated fatty acids, leading to lipid peroxidation and damage to the membranes of mitochondria, endoplasmic reticulum, and lysosomes, subsequently resulting in elevated levels of calcium and release of proteases in the cytoplasm (31, 32). It was observed that accumulation of ROS was increased to $46.75 \%$, the highest content, at $6 \mathrm{~h}$, and then decreased to $15.33 \%$ at $12 \mathrm{~h}$ of treatment of NCI-H1299 with EOPC (Suppl. Figure 5A, B). However, in citronellol-treated NCI-H1299 cells, ROS accumulation increased to $51.45 \%$ at $12 \mathrm{~h}$. Thus, citronellol-treated NCI-H1299 cells exhibited higher and longlasting ROS accumulation than EOPC-treated NCI-H1299 cells (Figure 2A, B, Figure Suppl. 5A, B). ROS production increased rapidly $1 \mathrm{~h}$ after both EOPC or citronellol treatment, stabilized between 3-9 h, and then increased again at $12 \mathrm{~h}$ after of citronellol treatment but not of EOPC treatment. The data indicated that there are two ROS accumulation pathways after EOPC or citronellol treatment, one was due to stimulation of the NCI-H1299 cells and the other was due to the necroptosis process. Citronellol treatment resulted in higher release of TNF- $\alpha$ which bound to TNFR, and activated Complexes I and II in NCI-H1299 cells, leading to more efficient and persistant ROS production. Over-accumulation of ROS leads to LMP, lysosomal rupture, and increase in cathepsin concentration (16). Accordingly, cathepsin B expression was substantially increased in a time-dependent manner after citronellol or EOPC treatment; but citronellol induced higher expression of cathepsin B compared to EOPC (Figure 2C, Suppl. Figure 5C, D). Therefore, the data indicated that citronellol causes lysosomal disruption, higher release of cathepsin in NCIH1299 cells, and more severe necroptosis than EOPC.

Xenograft model experiment showed that citronellol could effectively inhibit growth of subcutaneous tumours produced by subcutaneous inoculation of NCI-H1299 cells in BALB/c nude mice. Mice injected with high doses of citronellol $(50 \mathrm{mg} / \mathrm{kg})$ had tumour inhibition rate of up to $80 \%$.

In summary, our current study revealed that citronellol could trigger necroptosis by upregulating TNF- $\alpha$ expression and RIP1, RIP3 activities, down-regulating caspase-3 and caspase- 8 activity, and inducing over-activated PARP in NCI-H1299 cells. It also illustrated that there were two ROS accumulation pathways after citronellol treatment; one was to direct stimulation of NCI-H1299 cells and the other to the necroptosis process (Figure 4). It is expected that citronellol will be used to treat tumours in the future.

\section{Conflicts of Interest}

The Authors declare no conflicts of interest that might be construed to influence the results or interpretation of their manuscript.

\section{Authors' Contributions}

Study concept and design: Wan-Nien Yu, Jung-Yie Kao, Tzong-Der Way; Acquisition of data: Ying-Ju Lai, Jui-Wen Ma, Shan-Wei Hung; Analysis and interpretation of data: Ying-Ju Lai, Jui-Wen Ma, Shan-Wei Hung, Chiung-Tong Chen; Drafting of the manuscript: Wan-Nien Yu, Ying-Ju Lai; Reviewed manuscript: Chi-Tang Ho, Chiung-Tong Chen, Jung-Yie Kao, Tzong-Der Way.

\section{Acknowledgements}

The Authors thank all participants in this study.

\section{References}

1 Jemal A, Bray F, Center MM, Ferlay J, Ward E and Forman D: Global cancer statistics. CA Cancer J Clin 61(2): 69-90, 2011. PMID: 21296855. DOI: 10.3322/caac.20107

2 Reck M, Popat S, Reinmuth N, De Ruysscher D, Kerr KM and Peters S: Metastatic non-small-cell lung cancer (nsclc): Esmo clinical practice guidelines for diagnosis, treatment and followup. Ann Oncol 25(3): iii27-39, 2014. PMID: 25115305. DOI: 10.1093/annonc/mdu199

3 Ferlay J, Soerjomataram I, Dikshit R, Eser S, Mathers C, Rebelo M, Parkin DM, Forman D and Bray F: Cancer incidence and mortality worldwide: Sources, methods and major patterns in globocan 2012. Int J Cancer 136(5): E359-386, 2015. PMID:25220842. DOI: 10.1002/ijc.29210

4 Siegel RL, Miller KD and Jemal A: Cancer statistics, 2018. CA Cancer J Clin 68(1): 7-30, 2018. PMID: 29313949. DOI: 10.3322/caac. 21442

5 Pore MM, Hiltermann TJ and Kruyt FA: Targeting apoptosis pathways in lung cancer. CanceLett 332(2): 359-368, 2013. PMID: 20974517. DOI: 10.1016/j.canlet.2010.09.012

6 Green DR and Llambi F: Cell death signaling. Cold Spring Harb Perspect Biol 7(12), 2015. PMID: 26626938. DOI: 10.1101/ cshperspect.a006080

7 Nikoletopoulou V, Markaki M, Palikaras K and Tavernarakis N: Crosstalk between apoptosis, necrosis and autophagy. Biochim Biophys Acta 1833(12): 3448-3459, 2013. PMID: 23770045. DOI: $10.1016 /$ j.bbamcr.2013.06.001

8 Ou L, Lin S, Song B, Liu J, Lai R and Shao L: The mechanisms of graphene-based materials-induced programmed cell death: A review of apoptosis, autophagy, and programmed necrosis. Int $\mathrm{J}$ Nanomedicine 12: 6633-6646, 2017. PMID: 28924347. DOI: $10.2147 /$ IJN.S140526

9 Lalaoui N and Brumatti G: Relevance of necroptosis in cancer. Immunol Cell Biol 95(2): 137-145, 2017. PMID: 27922620. DOI: $10.1038 /$ icb.2016.120

10 Cho YS, Challa S, Moquin D, Genga R, Ray TD, Guildford M and Chan FK: Phosphorylation-driven assembly of the rip1-rip3 complex regulates programmed necrosis and virus-induced inflammation. Cell 137(6): 1112-1123, 2009. PMID: 19524513. DOI: $10.1016 /$ j.cell.2009.05.037

11 Christofferson DE and Yuan J: Necroptosis as an alternative form of programmed cell death. Curr Opin Cell Biol 22(2): 263268, 2010. PMID: 20045303. DOI:10.1016/j.ceb.2009.12.003

12 He S, Wang L, Miao L, Wang T, Du F, Zhao L and Wang X: Receptor interacting protein kinase-3 determines cellular 
necrotic response to TNF-alpha. Cell 137(6): 1100-1111, 2009. PMID: 19524512. DOI: 10.1016/j.cell.2009.05.021

13 Vanden Berghe T, Linkermann A, Jouan-Lanhouet S, Walczak H and Vandenabeele P: Regulated necrosis: The expanding network of non-apoptotic cell death pathways. Nat Rev Mol Cell Biol 15(2): 135-147, 2014. PMID: 24452471. DOI: 10.1038/nrm3737

14 Hanson B: Necroptosis: A new way of dying? Cancer Biol Ther 17(9): 899-910, 2016. PMID: 27434654. DOI: 10.1080/ 15384047.2016.1210732

15 Gomez-Sintes R, Hernandez F, Lucas JJ and Avila J: GSK-3 mouse models to study neuronal apoptosis and neurodegeneration. Front Mol Neurosci 4(45), 2011. PMID: 22110426. DOI: 10.3389/fnmol.2011.00045

16 Luo H, Liang H, Chen J, Xu Y, Chen Y, Xu L, Yun L, Liu J, Yang H, Liu L, Peng J, Liu Z, Tang L, Chen W and Tang H: Hydroquinone induces tk6 cell growth arrest and apoptosis through PARP-1/p53 regulatory pathway. Environ Toxicol 32(9): 2163-2171, 2017. PMID: 28444915. DOI: 10.1002/tox.22429

17 Morris G, Walker AJ, Berk M, Maes M and Puri BK: Cell death pathways: A novel therapeutic approach for neuroscientists. Mol Neurobiol 55(7): 5767-5786, 2018. PMID: 29052145. DOI: 10.1007/s12035-017-0793-y

18 Gunther C, Martini E, Wittkopf N, Amann K, Weigmann B, Neumann H, Waldner MJ, Hedrick SM, Tenzer S, Neurath MF and Becker C: Caspase-8 regulates TNF-alpha-induced epithelial necroptosis and terminal ileitis. Nature 477(7364): 335-339, 2011. PMID: 21921917. DOI: 10.1038/nature 10400

19 Kikuchi M, Kuroki S, Kayama M, Sakaguchi S, Lee KK and Yonehara S: Protease activity of procaspase-8 is essential for cell survival by inhibiting both apoptotic and nonapoptotic cell death dependent on receptor-interacting protein kinase 1 (RIP1) and RIP3. J Biol Chem 287(49): 41165-41173, 2012. PMID: 23071110. DOI: $10.1074 /$ jbc.M112.419747

20 Yuan J, Najafov A and Py BF: Roles of caspases in necrotic cell death. Cell 167(7): 1693-1704, 2016. PMID: 27984721. DOI: 10.1016/j.cell.2016.11.047

21 Vandenabeele P, Galluzzi L, Vanden Berghe T and Kroemer G: Molecular mechanisms of necroptosis: An ordered cellular explosion. Nat Rev Mol Cell Biol 11(10): 700-714, 2010. PMID: 20823910. DOI: $10.1038 / \mathrm{nrm} 2970$

22 Guerrini A, Rossi D, Paganetto G, Tognolini M, Muzzoli M, Romagnoli C, Antognoni F, Vertuani S, Medici A, Bruni A, Useli C, Tamburini E, Bruni $\mathrm{R}$ and Sacchetti G: Chemical characterization (GC/MS and NMR fingerprinting) and bioactivities of south-African Pelargonium capitatum (1.) l' her. (geraniaceae) essential oil. Chem Biodivers 8(4): 624-642, 2011. PMID: 21480508. DOI: 10.1002/cbdv.201000045

23 Victoria FN, Radatz CS, Sachini M, Jacob RG, Alves D, Savegnago L, Perin G, Motta AS, Silva WP and Lenardão EJ: Further analysis of the antimicrobial activity of $\alpha$-phenylseleno citronellal and $\alpha$-phenylseleno citronellol. Food Control 23(1): 95-99, 2012. DOI: 10.1016/j.foodcont.2011.06.017
24 Lopez-Romero JC, Gonzalez-Rios H, Borges A and Simoes M: Antibacterial effects and mode of action of selected essential oils components against Escherichia coli and Staphylococcus aureus. Evid Based Complement Alternat Med 2015: 795435, 2015. PMID: 26221178. DOI: 10.1155/2015/795435

$25 \mathrm{Lim}$ S and Shin S: Effects of citronellol and thymol on cell membrane composition of Candida albicans. Korean $\mathbf{J}$ Pharmacogn 40(4): 357-364, 2009.

26 Brito RG, Guimaraes AG, Quintans JS, Santos MR, De Sousa DP, Badaue-Passos D Jr., de Lucca W Jr., Brito FA, Barreto EO, Oliveira AP and Quintans LJ Jr.: Citronellol, a monoterpene alcohol, reduces nociceptive and inflammatory activities in rodents. J Nat Med 66(4): 637-644, 2012. PMID: 22350215. DOI: $10.1007 / \mathrm{s} 11418-012-0632-4$

27 Zhuang SR, Chen SL, Tsai JH, Huang CC, Wu TC, Liu WS, Tseng HC, Lee HS, Huang MC, Shane GT, Yang CH, Shen YC, Yan YY and Wang CK: Effect of citronellol and the Chinese medical herb complex on cellular immunity of cancer patients receiving chemotherapy/radiotherapy. Phytother Res 23(6): 785790, 2009. PMID: 19145638. DOI: 10.1002/ptr.2623

28 Bertoli C, Skotheim JM and de Bruin RA: Control of cell cycle transcription during G1 and S phases. Nat Rev Mol Cell Biol 14(8): 518-528, 2013. PMID: 23877564. DOI: 10.1038/nrm3629

29 Roy D, Sheng GY, Herve S, Carvalho E, Mahanty A, Yuan S and Sun L: Interplay between cancer cell cycle and metabolism: Challenges, targets and therapeutic opportunities. Biomed Pharmacother 89: 288-296, 2017. PMID: 28235690. DOI: 10.1016/j.biopha.2017.01.019

30 Mendelsohn AR and Larrick JW: The NAD+/PARP1/SIRT1 axis in aging. Rejuvenation Res 20(3): 244-247, 2017. PMID: 28537485. DOI: 10.1089/rej.2017.1980

$31 \mathrm{Li} \mathrm{L}$, Tan J, Miao Y, Lei P and Zhang Q: Ros and autophagy: Interactions and molecular regulatory mechanisms. Cell Mol Neurobiol 35(5): 615-621, 2015. PMID: 25722131. DOI: 10.1007/s10571-015-0166-x

32 Prasad S, Gupta SC and Tyagi AK: Reactive oxygen species (ROS) and cancer: Role of antioxidative nutraceuticals. Cancer Lett 387: 95-105, 2017. PMID: 27037062. DOI: 10.1016/ j.canlet.2016.03.042
Received March 20, 2019

Revised May 20, 2019

Accepted May 23, 2019 